\title{
Agonists of Peroxisome-Proliferator Activated Receptor-Gamma Reduce Renal Ischemia/Reperfusion Injury
}

\author{
Ahila Sivarajah $^{a}$ Prabal K. Chatterjee ${ }^{a}$ Nimesh S.A. Patel ${ }^{a}$ \\ Zoran Todorovic $^{a}$ Yoshiyuki Hattori ${ }^{b}$ Paul A.J. Brown ${ }^{c}$ Keith N. Stewart ${ }^{c}$ \\ Helder Mota-Filipe ${ }^{d}$ Salvatore Cuzzocrea ${ }^{\mathrm{e}}$ Christoph Thiemermann ${ }^{a}$ \\ aDepartment of Experimental Medicine and Nephrology, William Harvey Research Institute, Queen Mary - \\ University of London, UK; b Department of Endocrinology and Metabolism, Dokkyo University School of Medicine, \\ Mibu, Japan; ' Departments of Pathology and Medicine and Therapeutics, University of Aberdeen, Aberdeen, UK; \\ dLaboratory of Pharmacology, Faculty of Pharmacy, University of Lisbon, Portugal; eDepartment of Clinical and \\ Experimental Medicine and Pharmacology, Institute of Pharmacology, School of Medicine, University of Messina, \\ Messina, Italy
}

\section{Key Words}

Kidney $\cdot$ Reperfusion-injury $\cdot$ Renal dysfunction •

Peroxisome-proliferator activated receptor .

Rosiglitazone $\cdot$ Ciglitazone $\cdot$ Intercellular adhesion molecule-1

\begin{abstract}
Background/Aims: Recent evidence indicates that peroxisome-proliferator activated receptor (PPAR) agonists protect against ischemia/reperfusion (I/R) injury. Here we investigate the effects of the PPAR- $\gamma$ agonists, rosiglitazone and ciglitazone, on the renal dysfunction and injury caused by I/R of the rat kidney in vivo. Methods: Rosiglitazone or ciglitazone were administered to male Wistar rats prior to and during reperfusion. Biochemical indicators of renal dysfunction and injury were measured and histological scoring of kidney sections was used to assess renal injury. Expression of PPAR isoforms and intercellular adhesion molecule-1 during renal $\mathrm{I} / \mathrm{R}$ were assessed using RT-PCR and Northern blot, respectively.
\end{abstract}

Myeloperoxidase activity and activation of poly(ADPribose) polymerase (PARP) were used as indicators of polymorphonuclear (PMN) cell infiltration and oxidative stress, respectively. Results: Expression of PPAR- $\alpha$, PPAR- $\beta$ and PPAR- $\gamma 1$ (but not PPAR- $\gamma 2$ ) was observed in kidneys with down-regulation of PPAR- $\alpha$ expression during renal I/R. Rosiglitazone and ciglitazone significantly reduced biochemical and histological signs of renal dysfunction and injury. Renal expression of ICAM-1 caused by $\mathrm{I} / \mathrm{R}$ was reduced by rosiglitazone and ciglitazone which was reflected by decreased PMN infiltration into reperfused renal tissues. Both rosiglitazone and ciglitazone reduced PARP activation indicating a reduction of oxidative stress. Conclusion: These results suggest that the PPAR- $\gamma$ agonists rosiglitazone and ciglitazone reduce the renal dysfunction and injury associated with $\mathrm{I} / \mathrm{R}$ of the kidney. We propose that one mechanism underlying the protective effects involves inhibition of the expression of ICAM-1, a reduction of PMN infiltration into renal tissues and subsequent reduction of oxidative stress.

Copyright $@ 2003$ S. Karger AG, Basel

Prof. Christoph Thiemermann

Department of Experimental Medicine and Nephrology

William Harvey Research Institute, Queen Mary - University of London

Charterhouse Square, London, EC1M 6BQ (UK)

Tel. +44 207882 6118, Fax +44 207251 1685, E-Mail c.thiemermann@qmul.ac.uk 


\section{Introduction}

Peroxisome proliferator-activated receptors (PPARs) are members of the nuclear hormone receptor superfamily of ligand-activated transcription factors that are related to retinoid, steroid and thyroid hormone receptors [1]. The PPAR subfamily comprises of three members, PPAR- $\alpha$, PPAR- $\beta$, and PPAR- $\gamma$ and most tissues in humans (and rodents) express all three receptor subtypes, although there is considerable variability in relative expression [1]. Multiple splicing forms of PPAR- $\gamma$ (PPAR- $\gamma 1$, PPAR- $\gamma 2$ and, in humans, PPAR- $\gamma 3$ ) have been identified, which are derived from a single gene as a result of differential splicing and alternate promoter usage [1]. PPAR- $\gamma 1$ is the major isoform, e.g. accounting for approximately $85 \%$ of PPARs in adipose tissues [2], in contrast, no mRNA splice variants for PPAR- $\alpha$ and $-\beta$ have been identified $[1,2]$. PPARs regulate gene expression by binding, as heterodimers with retinoid X receptors (RXRs), to specific PPAR response elements (PPREs) in the promoter regions of specific target genes [2]. In the absence of a ligand, high affinity complexes are formed between the PPAR-RXR heterodimer and nuclear receptor co-repressor proteins, preventing interaction of the heterodimer with the PPRE thereby preventing transcriptional activation. Binding of a ligand to the heterodimer results in the release of the co-repressor from the complex, followed by the binding of the activated heterodimer to the response element in the promoter region of relevant target genes [2].

Despite significant advances in critical care medicine, acute renal failure (ARF) remains a major clinical problem, causing considerable morbidity and mortality which has not decreased significantly over the last 50 years [3]. Previous interventions against ARF have proved to be largely negative and dialysis still remains the only effective therapy [4]. Thus, the development of novel therapeutic interventions against ARF has remained a topic of research interest [3,4]. Renal ischemia initiates a complex and interrelated sequence of events, resulting in the injury and death of renal cells [5, 6]. Reperfusion, although essential for the survival of ischemic renal tissue, causes additional damage (reperfusion-injury) [7]. Together, ischemia/reperfusion (I/R) of the kidney contribute to the renal dysfunction and injury associated with ischemic ARF $[6,8]$. The recent development of a novel class of insulin-sensitising drugs, the thiazolidinediones (TZDs), represents a significant advance in anti-diabetic therapy [9]. There is now good evidence that these TZDs may also provide beneficial actions against inflammation and cancer via activation of the PPAR- $\gamma$ [9]. Rosiglitazone is the most potent and selective PPAR- $\gamma$ agonist [10] and there is a good correlation between the potency of the TZDs as PPAR- $\gamma$ agonists in vitro and their efficacy in lowering glucose levels in vivo [11]. PPAR- $\gamma$ agonists have also been shown to protect the intestine [12-14], lung [15] and heart [16-20] against I/R injury. Although there is evidence that rosiglitazone can reduce nephropathy in diabetic Zucker fatty rats [21] and that another PPAR- $\gamma$ agonist, troglitazone, can protect against non-diabetic glomerulosclerosis in rats [22], there are, to our knowledge, no studies which have investigated the effects of PPAR- $\gamma$ agonists against $\mathrm{I} / \mathrm{R}$ injury of the kidney.

To test our hypothesis that PPAR- $\gamma$ agonists could reduce the renal I/R injury, thereby ameliorating a major cause of ischemic ARF, we investigated the effects of the PPAR- $\gamma$ ligands rosiglitazone and ciglitazone on the renal injury and dysfunction caused by ischemia and reperfusion in the anesthetized rat. Having discovered that both rosiglitazone and ciglitazone reduced renal dysfunction and injury, we performed further studies aimed at elucidating the mechanisms by which these TZDs protect the kidney against I/R injury. Specifically, we investigated how rosiglitazone and ciglitazone can modulate the following during renal I/R: (i) the expression of the different isoforms of PPAR; (ii) expression of intercellular adhesion molecule-1 (ICAM-1); (iii) polymorphonuclear $(\mathrm{PMN})$ cell infiltration into reperfused tissues, and (iv) activation of poly (ADP-ribose) polymerase (PARP) activation which was used as an indicator of oxidative stress.

\section{Methods}

\section{Renal Ischemia/Reperfusion}

In vivo studies were carried out on 65 male Wistar rats (Tuck, Rayleigh, Essex, UK). Anesthetized rats were subjected to bilateral renal ischemia for $45 \mathrm{~min}$ followed by reperfusion for $6 \mathrm{~h}$ as described previously $[23,24]$. Upon completion of surgical procedures, the animals were randomly allocated into ten groups as described below:

(1) I/R + VEH group: Rats which underwent renal ischemia for $45 \mathrm{~min}$ followed by reperfusion for $6 \mathrm{~h}$ and received bolus injections of the vehicle for rosiglitazone and ciglitazone $(10 \%$ [v/v] dimethylsulfoxide [DMSO], $\mathrm{n}=7$ ).

(2) I/R + ROS 0.3 group: Rats which were administered rosiglitazone $(0.3 \mathrm{mg} / \mathrm{kg}$ i.v. bolus $) 5 \mathrm{~min}$ prior to and $3 \mathrm{~h}$ after commencement of reperfusion $(n=6)$.

(3) I/R + ROS 1 group: Rats which were administered rosiglitazone ( $1 \mathrm{mg} / \mathrm{kg}$ i.v. bolus) $5 \mathrm{~min}$ prior to and $3 \mathrm{~h}$ after commencement of reperfusion $(\mathrm{n}=11)$.

(4) I/R + ROS 3 group: Rats which were administered rosiglitazone ( $3 \mathrm{mg} / \mathrm{kg}$ i.v. bolus) $5 \mathrm{~min}$ prior to and $3 \mathrm{~h}$ after commencement of reperfusion $(n=7)$. 
(5) $\mathrm{I} / \mathrm{R}+\mathrm{CIG} 0.3$ group: Rats were administered ciglitazone $(0.3 \mathrm{mg} / \mathrm{kg}$ i.v. bolus) $5 \mathrm{~min}$ prior to $3 \mathrm{~h}$ after commencement of reperfusion $(\mathrm{n}=6)$.

(6) I/R + CIG 1 group: Rats were administered ciglitazone ( $1 \mathrm{mg} /$ $\mathrm{kg}$ i.v. bolus) $5 \mathrm{~min}$ prior to and $3 \mathrm{~h}$ after commencement of reperfu$\operatorname{sion}(\mathrm{n}=7)$.

(7) I/R + CIG 3 group: Rats were administered ciglitazone ( $3 \mathrm{mg} /$ $\mathrm{kg}$ i.v. bolus) $5 \mathrm{~min}$ prior to and $3 \mathrm{~h}$ after commencement of reperfusion $(\mathrm{n}=7)$.

(8) Sham + VEH group: Rats which were subjected to identical surgical procedures described above except for renal I/R. Rats were administered bolus injections of the vehicle $(2 \mathrm{ml} / \mathrm{kg} 10 \%$ [v/v] DMSO) at times equivalent to those described above $(\mathrm{n}=6)$.

(9) Sham + ROS 3 group: Identical to sham-operated animals except for administration of rosiglitazone ( $3 \mathrm{mg} / \mathrm{kg}$ i.v. bolus) $(\mathrm{n}=4)$.

(10) Sham + CIG 3 group: Identical to sham-operated animals except for administration of ciglitazone $(3 \mathrm{mg} / \mathrm{kg}$ i.v. bolus $)(\mathrm{n}=4)$.

Rats were maintained under anesthesia for the duration of the experiment (i.e. $45 \mathrm{~min}+6 \mathrm{~h}$ ).

\section{Measurement of Biochemical Parameters}

At the end of the reperfusion period, blood $(1 \mathrm{ml})$ and urine samples were collected and used for the measurement of biochemical renal parameters as described previously [23, 24]. Briefly, serum samples were used for the measurement of serum urea and creatinine levels, which were used as indicators of impaired glomerular function $[23,24]$. Urine samples were collected throughout the reperfusion period and the volume of urine produced recorded. Urine concentrations of creatinine and $\mathrm{Na}^{+}$were measured and used in conjunction with serum creatinine, $\mathrm{Na}^{+}$and urine flow to estimate creatinine clearance and fractional excretion of $\mathrm{Na}^{+}$. Creatinine clearance provided an indication of glomerular filtration rate and glomerular dysfunction whereas fractional excretion of $\mathrm{Na}^{+}$was used as an indicator of tubular function/dysfunction [23, 24]. Additionally, urinary Nacetyl- $\beta-D$-glucosaminidase activity, an indicator of tubular damage, and possibly tubular function, was also measured (Clínica Médica e Diagnóstico Dr. Joaquim Chaves, Lisbon, Portugal) [24].

\section{Histological Evaluation}

Renal sections were prepared as described previously and used for the assessment of renal I/R injury [24]. Briefly, one hundred intersections were examined for each kidney and a score from 0 to 3 was given for each tubular profile involving an intersection: $0=$ normal histology; 1 = tubular cell swelling, brush border loss, nuclear condensation, with up to $1 / 3$ of tubular profile showing nuclear loss; 2 = as for score 1 , but greater than $1 / 3$ and less than $2 / 3$ of tubular profile shows nuclear loss, and $3=$ greater than $2 / 3$ of tubular profile shows nuclear loss. The total score for each kidney was calculated by addition of all 100 scores with a maximum score of 300 .

\section{RT-PCR for PPAR Isoforms}

Total RNA was extracted from the kidney tissues (immediately snap frozen in liquid nitrogen and stored at $-70^{\circ} \mathrm{C}$ ) using the guanidinium isothiocyanate/acid phenol method [25]. Contaminated DNA was eliminated from RNA preparation using DNA-free RNA $^{\mathrm{TM}}$ kit (Zymo Research, Tokyo, Japan). RT-PCR analysis for PPAR isoforms was performed as previously described, using synthetic gene-specific primers derived from the published sequences for rat PPAR [17].

PPAR- $\gamma$ Agonists Reduce Renal

Ischemia/Reperfusion Injury
Northern Blot Analysis of ICAM-1 mRNA Expression

ICAM-1 mRNA levels were evaluated by Northern blot analysis. RNA prepared from rat kidney was reverse-transcribed, and the resulting cDNA was amplified by the PCR method using primers specific for rat ICAM-1. The following primers used were: forward: GGGTTGGAGACTAACTGGA; reverse: CCTCTGGCCGGTAATAGGTG. The PCR product for ICAM $(1,384 \mathrm{bp})$ was used as a probe after sequence confirmation. The ICAM-1 probe was labelled with $\left[\alpha_{-}{ }^{32} \mathrm{P}\right] \mathrm{dCTP}$ using random priming. Northern blot procedures were performed as previously described [17]. After probing for ICAM-1 expression, filters were stripped and re-probed for the presence of glyceraldehyde-3-phosphate dehydrogenase (GAPDH) mRNA, as described previously [17]. The blots were exposed to an imaging plate (Fuji Photo Film Co., Tokyo, Japan) at room temperature for $6 \mathrm{~h}$ and analyzed using a FUJIX bioimaging analyzer (BAS2000II, Fuji Photo Film Co.).

\section{Immunohistochemical Localisation of Poly (ADP-Ribose)}

Immunohistochemical localisation of PAR (indicative of PARP activation) in kidney sections was performed as previously described [23]. Kidneys were fixed in 10\% formalin buffered using phosphatebuffered saline (PBS, $0.01 M$, pH 7.4) and 8- $\mu \mathrm{m}$ sections were prepared from paraffin embedded tissues. After deparaffinization, endogenous peroxidase was quenched with $0.3 \%(\mathrm{v} / \mathrm{v})$ hydrogen peroxide in $60 \%(\mathrm{v} / \mathrm{v})$ methanol for $30 \mathrm{~min}$. Sections were then permeabilized with $0.1 \%(\mathrm{v} / \mathrm{v})$ Triton X-100 in PBS for $20 \mathrm{~min}$ and nonspecific adsorption was minimised by incubation in $2 \%(\mathrm{w} / \mathrm{v})$ normal goat serum in PBS for $20 \mathrm{~min}$. Endogenous biotin or avidin binding sites were blocked by sequential incubation for $15 \mathrm{~min}$ with avidin and biotin (DBA, Milan, Italy). Sections were then incubated overnight at $4{ }^{\circ} \mathrm{C}$ with primary anti-PAR antibody (1:500 [v/v] in PBS) (DBA, Milan, Italy) or with control solutions which included incubation with buffer alone or non-specific purified rabbit IgG (DBA). Specific labelling of antigen-antibody complex was visualised using a biotin-conjugated goat anti-rabbit IgG (DBA) and avidin-biotin peroxidase complex (DBA) immunoperoxidase technique using chromogen diaminobenzidine.

\section{Determination of Myeloperoxidase Activity}

Myeloperoxidase (MPO) activity in kidneys was used as an indicator of PMN infiltration using a method previously described [24]. Briefly, at the end of the experiments, kidney tissue was weighed and homogenised in a solution containing $0.5 \%(\mathrm{w} / \mathrm{v})$ hexadecyltrimethylammonium bromide dissolved in $10 \mathrm{~m} M$ potassium phosphate buffer ( $\mathrm{pH} 7.4$ ) and centrifuged for $30 \mathrm{~min}$ at $20,000 \mathrm{~g}$ at $4{ }^{\circ} \mathrm{C}$. An aliquot of supernatant was then removed and added to a reaction mixture containing $1.6 \mathrm{~m} M$ tetramethylbenzidine and $0.1 \mathrm{~m} M$ hydrogen peroxide. The rate of change in absorbance was measured spectrophotometrically at $650 \mathrm{~nm}$. MPO activity was defined as the quantity of enzyme required for the degradation of $1 \mu \mathrm{mol}$ of $\mathrm{H}_{2} \mathrm{O}_{2}$ at $37^{\circ} \mathrm{C}$ and was expressed in milliunits $/ 100 \mathrm{mg}$ wet tissue.

\section{Materials}

Unless otherwise stated, all compounds used in this study were purchased from Sigma-Aldrich Company Ltd. (Poole, Dorset, UK). All solutions used in vivo were prepared using non-pyrogenic saline $(0.9 \%[\mathrm{w} / \mathrm{v}] \mathrm{NaCl}$; Baxter Healthcare Ltd., Thetford, Norfolk, UK). Stock solutions of rosiglitazone and ciglitazone (Alexis Biochemicals, Bingham, Nottingham, UK) were prepared in $10 \%(\mathrm{v} / \mathrm{v})$ DMSO and $90 \%(\mathrm{v} / \mathrm{v})$ saline. 


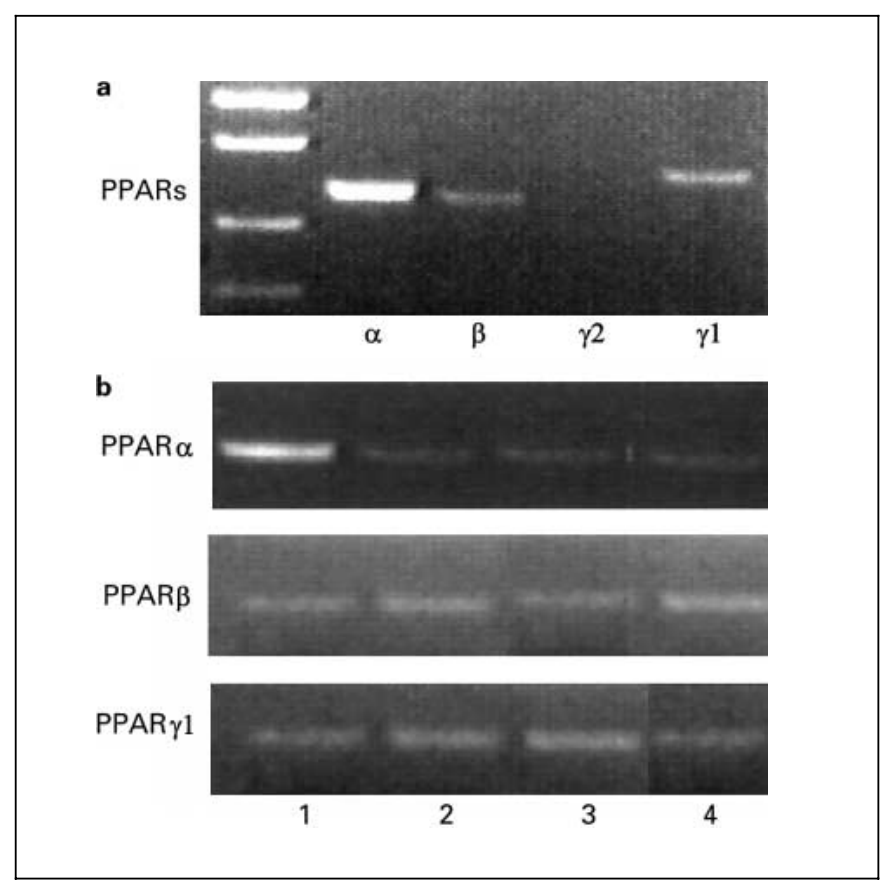

Fig. 1. PPAR expression in rat kidneys (RT-PCR analysis). a Rats were subjected to surgical procedure alone and administered 10\% (v/v) DMSO (Sham + VEH, $2 \mathrm{ml} / \mathrm{kg}$ i.v.). b Rats were subjected to (1) surgical procedure alone and treated with $10 \%(\mathrm{v} / \mathrm{v}) \mathrm{DMSO}$ ( $2 \mathrm{ml} / \mathrm{kg}$ i.v.); (2) to bilateral renal I/R and administered 10\% DMSO ( $2 \mathrm{ml} / \mathrm{kg}$ i.v.); (3) $3 \mathrm{mg} / \mathrm{kg}$ rosiglitazone i.v., or (4) $1 \mathrm{mg} / \mathrm{kg}$ ciglitazone i.v.

\section{Statistical Analysis}

All values described in the text and figures are expressed as mean \pm SEM for $n$ observations. For in vivo studies, each data point represents biochemical measurements obtained from 4 to 11 separate animals. For histological scoring, each data point represents analysis of kidneys taken from 4-8 individual animals. For molecular biology assays (RT-PCR and Northern blotting) and immunohistochemical analysis, figures shown are representative of at least 3 experiments performed on different experimental days and statistical analysis performed on data obtained from kidneys taken from a minimum of 4 rats per treatment group. Statistical analysis was carried out using GraphPad Prism/Instat 1.1 (GraphPad Software, San Diego, Calif., USA). Data were analysed using one-way ANOVA followed by Dunnett's post hoc test. $\mathrm{p}<0.05$ was considered to be significant.

\section{Results}

Effect of I/R on the Expression of PPAR Isoforms in the Kidney

Products of expected size [17] were obtained for the PPAR isoforms (523 bp for PPAR- $\alpha, 496$ bp for PPAR- $\beta$, and $614 \mathrm{bp}$ for PPAR- $\gamma 1$ ) from the kidneys of rats sub- jected to sham operation (fig. 1a). Although no PCR product specific for PPAR- $\gamma 2$ was observed (fig. 1a), this isoform was subsequently detected in adipose tissue (data not shown). Renal I/R caused a down-regulation of PPAR- $\alpha$ expression; however, I/R did not have an effect on the expression of either PPAR- $\gamma 1$ or PPAR- $\beta$ (fig. $1 b$ ). Administration of rosiglitazone or ciglitazone did not have any effect on the down-regulation of PPAR- $\alpha$ caused by renal I/R or on PPAR- $\beta$ or PPAR- $\gamma 1$ expression during renal I/R (fig. 1b).

\section{Effect of Rosiglitazone and Ciglitazone on Glomerular Dysfunction Caused by Renal I/R}

When compared to sham-operated rats, I/R caused a significant increase in serum levels of urea and creatinine (fig. 2a, b) suggesting marked glomerular dysfunction. This was reflected by a significant attenuation in glomerular filtration rate, which was measured as creatinine clearance (fig. 2c). Administration of rosiglitazone caused a dose-dependent reduction in serum levels of urea and creatinine with a significant reduction observed using the highest dose of rosiglitazone administered $(3 \mathrm{mg} / \mathrm{kg})$ (fig. 2a, b). A similar profile was observed in creatinine clearance with the highest dose of rosiglitazone $(3 \mathrm{mg} / \mathrm{kg})$ providing a significant improvement (fig. 2c). Administration of ciglitazone also produced a significant reduction in serum levels of urea and creatinine and a significant improvement in creatinine clearance; however, the largest improvement in glomerular function was obtained after ciglitazone was administered at $1 \mathrm{mg} / \mathrm{kg}$ (fig. 2a-c). In sham-operated rats, administration of rosiglitazone or ciglitazone did not modulate serum levels of urea or creatinine and did not affect creatinine clearance when compared to values measured from sham-operated rats administered 10\% (v/v) DMSO only (table 1).

\section{Effect of Rosiglitazone and Ciglitazone on Tubular Dysfunction/Injury Caused by Renal I/R}

Fractional excretion of $\mathrm{Na}^{+}$was used as an indicator of tubular dysfunction. When compared to sham-operated rats, I/R caused a significant increase in fractional excretion of $\mathrm{Na}^{+}$suggesting marked tubular dysfunction (fig. 3a). Administration of rosiglitazone or ciglitazone (1 and $3 \mathrm{mg} / \mathrm{kg}$ ) significantly attenuated the tubular dysfunction caused by I/R (fig. 3a). In sham-operated rats, neither rosiglitazone nor ciglitazone had any significant effect on fractional excretion of $\mathrm{Na}^{+}$when compared to values measured from sham-operated rats administered $10 \%(\mathrm{v} / \mathrm{v})$ DMSO only (table 1). 
Urinary $\mathrm{N}$-acetyl- $\beta$ - $D$-glucosaminidase activity was used as an indicator of tubular injury. When compared to sham-operated rats, I/R caused a significant increase in $\mathrm{N}$-acetyl- $\beta-D$-glucosaminidase enzymuria, suggesting tubular injury (fig. 3b). Administration of rosiglitazone or ciglitazone ( 1 and $3 \mathrm{mg} / \mathrm{kg}$ ) significantly attenuated urinary $\mathrm{N}$-acetyl- $\beta-D$-glucosaminidase activity suggesting a significant reduction of the tubular injury caused by I/R (fig. 3b). In sham-operated rats, neither rosiglitazone nor ciglitazone had any significant effect on urinary $\mathrm{N}$-acetyl$\beta$ - $D$-glucosaminidase activity when compared to values measured from sham-operated rats administered $10 \%$ (v/v) DMSO only (table 1).

When compared to the histological score measured from kidneys obtained from sham-operated animals, a significant increase in histological score was recorded from rats subjected to $I / R$, indicating significant tubular injury (fig. 3c). Histological scores were significantly reduced by administration of rosiglitazone ( 1 and $3 \mathrm{mg} / \mathrm{kg}$ ) or ciglitazone ( 1 and $3 \mathrm{mg} / \mathrm{kg}$ ) (fig. 3c). Administration of rosiglitazone or ciglitazone to sham-operated rats did not have any effect on histological score when compared to values obtained from sham-operated rats administered $10 \%$ (v/v) DMSO only (table 1).

Fig. 2. Effects of rosiglitazone and ciglitazone on renal dysfunction caused by I/R. Alterations in serum urea (a), serum creatinine (b) and creatinine clearance (c) in rats subjected to surgical procedure alone and administered 10\% (v/v) DMSO (Sham + VEH, $2 \mathrm{ml} / \mathrm{kg}$ i.v., $\mathrm{n}=6$ ), or in rats subjected to bilateral renal I/R and treated with $10 \%(\mathrm{v} / \mathrm{v})$ DMSO (I/R + VEH, $2 \mathrm{ml} / \mathrm{kg}$ i.v., $\mathrm{n}=7$ ), rosiglitazone (I/R $+\operatorname{ROS} 0.3, \mathrm{I} / \mathrm{R}+\operatorname{ROS} 1$ or I/R + ROS 3, 0.3, 1 or $3 \mathrm{mg} / \mathrm{kg}$ i.v., $\mathrm{n}=$ 6-11) or ciglitazone (I/R + CIG 0.3, I/R + CIG 1 or I/R + CIG 3, 0.3, 1 or $3 \mathrm{mg} / \mathrm{kg}$ i.v., $\mathrm{n}=6-7$ ) prior to and during reperfusion. Data are expressed as mean \pm SEM of $n$ observations, ${ }^{*} p<0.05$ vs. I/R + VEH.
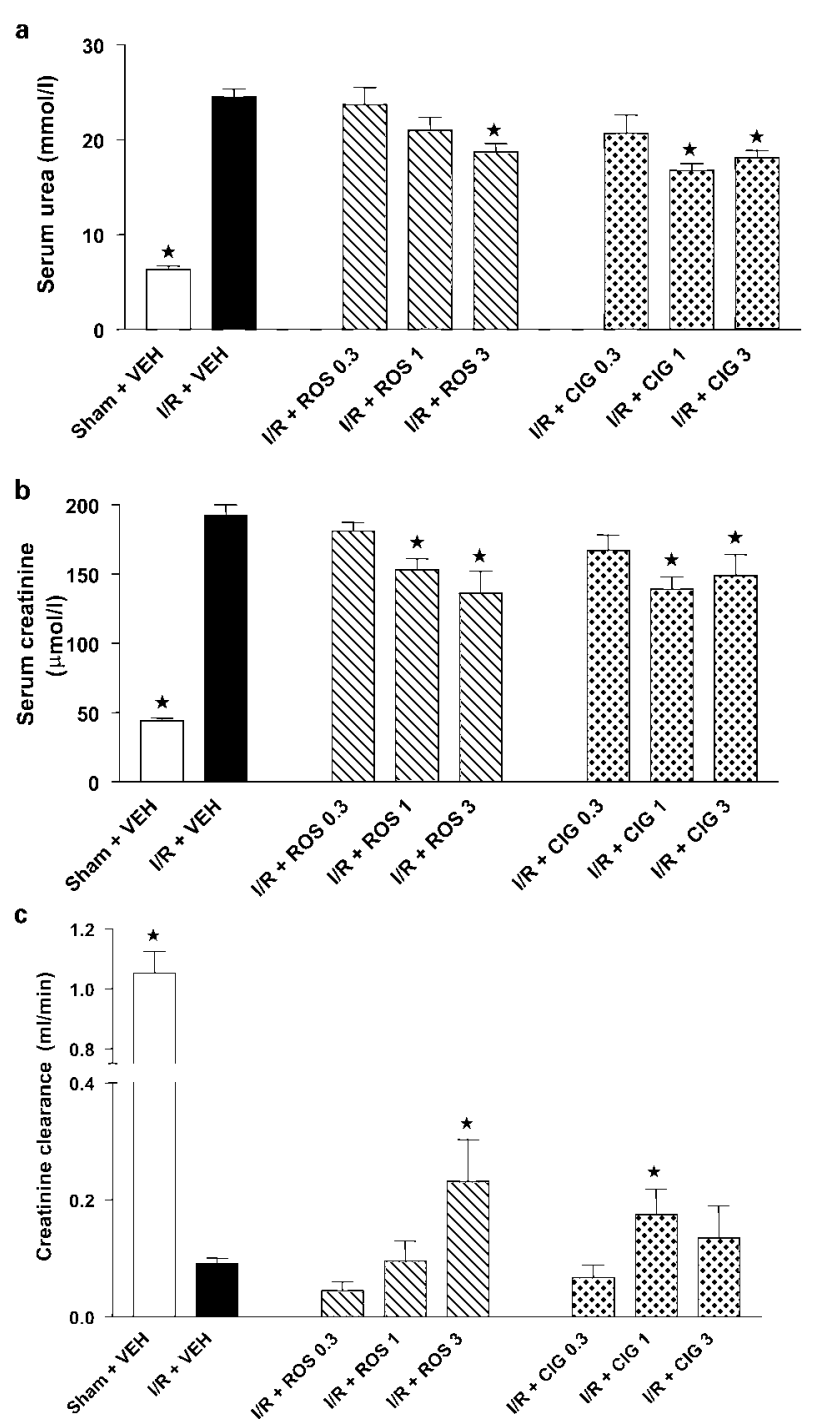

Table 1. Renal function in sham-operated rats

\begin{tabular}{lllllll}
\hline & $\begin{array}{l}\text { Serum } \\
\text { urea } \\
\mathrm{mmol} / 1\end{array}$ & $\begin{array}{l}\text { Serum } \\
\text { creatinine clearance } \\
\mu \mathrm{mol} / 1\end{array}$ & $\begin{array}{l}\text { Creatinine } \\
\mathrm{ml} / \mathrm{min}\end{array}$ & $\begin{array}{l}\text { Fractional } \\
\text { excretion of } \\
\mathrm{Na}^{+}, \%\end{array}$ & $\begin{array}{l}\mathrm{NAG} \\
\text { activity } \\
\text { IU/1 }\end{array}$ & $\begin{array}{l}\text { Histological } \\
\text { score } \\
\text { (out of 300) }\end{array}$ \\
\hline Sham + VEH & $6.3 \pm 0.4$ & $44 \pm 2$ & $1.503 \pm 0.072$ & $0.79 \pm 0.13$ & $3.1 \pm 1.9$ & $0 \pm 0$ \\
Sham + ROS 3 & $5.0 \pm 0.9$ & $43 \pm 2$ & $1.247 \pm 0.130$ & $1.44 \pm 0.17$ & $3.5 \pm 0.9$ & $0 \pm 0$ \\
Sham + CIG 3 & $4.5 \pm 0.6$ & $43 \pm 1$ & $1.450 \pm 0.210$ & $1.25 \pm 0.10$ & $4.1 \pm 1.2$ & $0 \pm 0$ \\
\hline
\end{tabular}

Rats were subjected to sham-operation and administered either 10\% (v/v) DMSO (Sham + VEH, $2 \mathrm{ml} / \mathrm{kg}$ i.v., $\mathrm{n}=6$ ), rosiglitazone (Sham + ROS 3, $3 \mathrm{mg} / \mathrm{kg}$ i.v., $\mathrm{n}=4$ ), or ciglitazone $(\mathrm{Sham}+\mathrm{CIG} 3,3 \mathrm{mg} / \mathrm{kg}$ i.v., $\mathrm{n}=4)$. Data are expressed as mean \pm SEM of $n$ observations. 


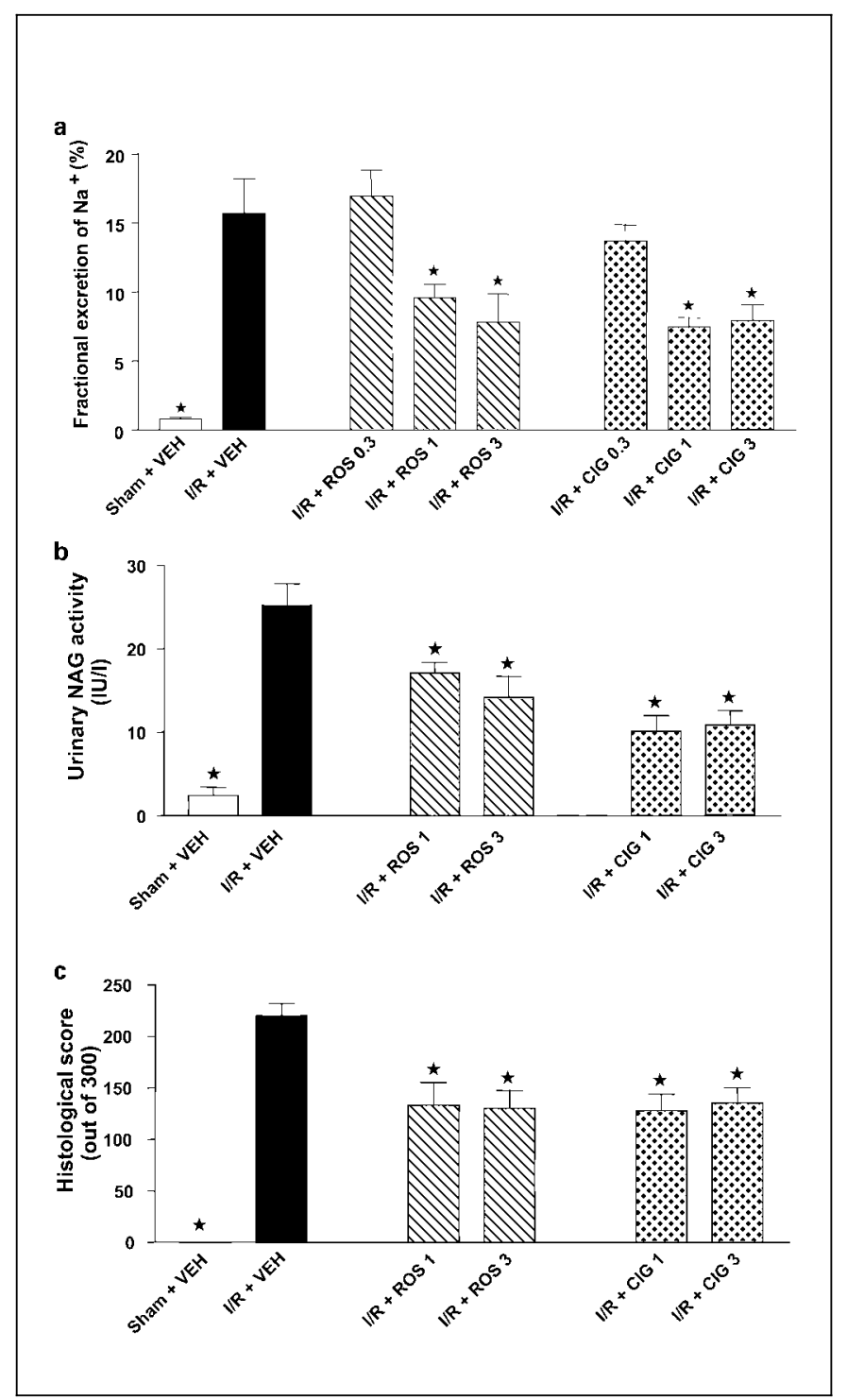

Fig. 3. Effects of rosiglitazone and ciglitazone on tubular dysfunction and injury caused by renal I/R. Alterations in fractional excretion of $\mathrm{Na}^{+}(\mathbf{a})$; urinary $\mathrm{N}$-acetyl- $\beta-D$-glucosaminidase activity (b) and Histological Score (out of 300) (c) in rats subjected to surgical procedure alone and administered 10\% (v/v) DMSO (Sham + VEH, $2 \mathrm{ml} / \mathrm{kg}$ i.v., $\mathrm{n}=6$ ), or in rats subjected to bilateral renal $\mathrm{I} / \mathrm{R}$ and treated with $10 \%$ (v/v) DMSO (I/R + VEH, $2 \mathrm{ml} / \mathrm{kg}$ i.v., $\mathrm{n}=7$ ), rosiglitazone (I/R $+\operatorname{ROS} 0.3, \mathrm{I} / \mathrm{R}+\operatorname{ROS} 1$ or $\mathrm{I} / \mathrm{R}+\operatorname{ROS~} 3,0.3,1$ or $3 \mathrm{mg} / \mathrm{kg}$ i.v., $\mathrm{n}=$ 6-11) or ciglitazone (I/R + CIG 0.3, I/R + CIG 1 or I/R + CIG 3, 0.3, 1 or $3 \mathrm{mg} / \mathrm{kg}$ i.v., $\mathrm{n}=6-7$ ) prior to and during reperfusion. Data are expressed as mean \pm SEM of $n$ observations, ${ }^{*} \mathrm{p}<0.05$ vs. I/R + VEH.

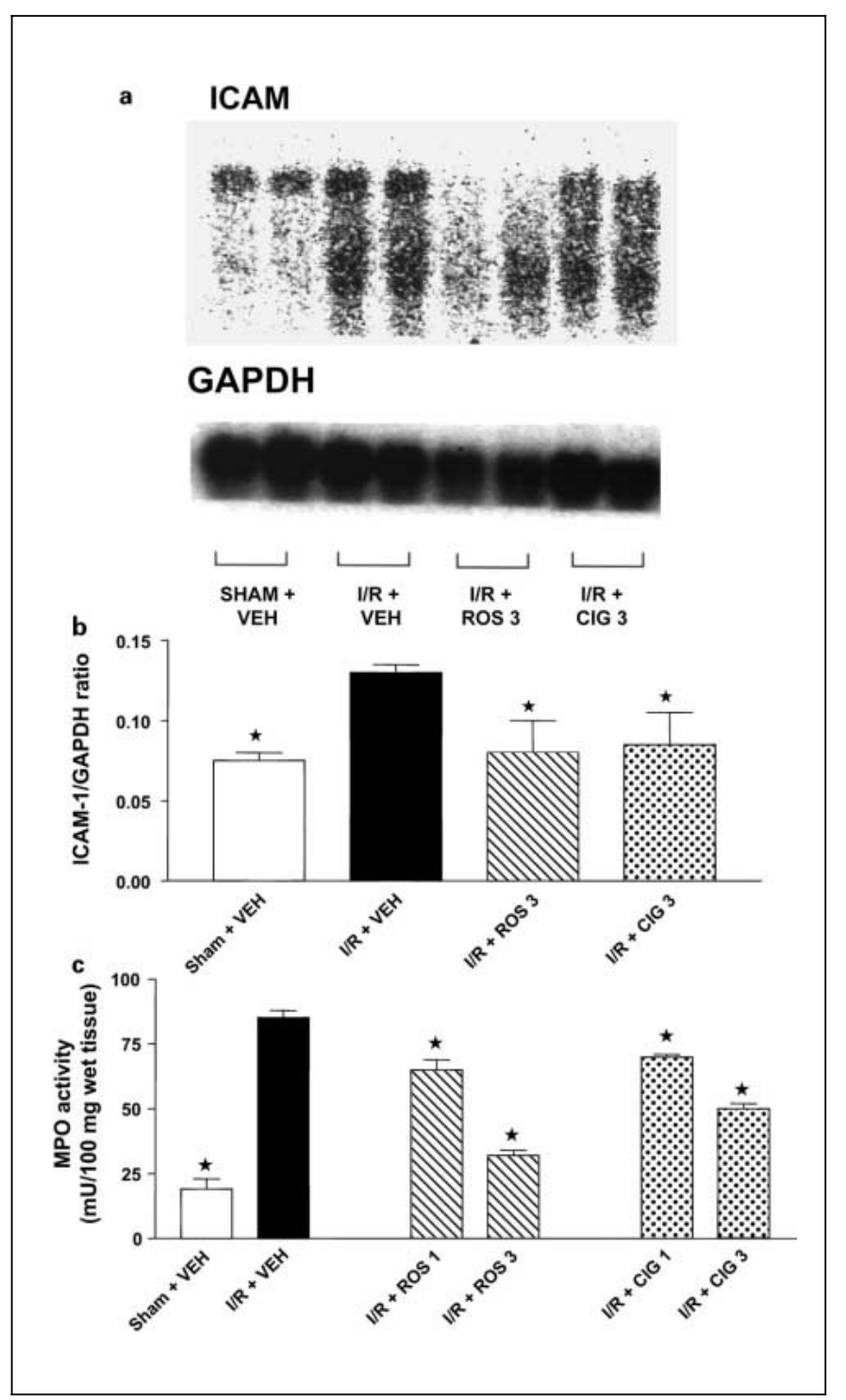

Fig. 4. Effect of rosiglitazone and ciglitazone on expression of ICAM-1 and GAPDH mRNA in rat kidney (Northern blot analysis) (a); ratio of ICAM-1 to GAPDH mRNA expression (b), and PMN infiltration (kidney myeloperoxidase activity) (c). Rats were subjected to surgical procedure alone and administered $10 \%(\mathrm{v} / \mathrm{v})$ DMSO (Sham + VEH, $2 \mathrm{ml} / \mathrm{kg}$ i.v., $\mathrm{n}=6$ ), or in rats subjected to bilateral renal I/R and treated with $10 \%$ (v/v) DMSO (I/R + VEH, $2 \mathrm{ml} / \mathrm{kg}$ i.v., $\mathrm{n}=7$ ), rosiglitazone (I/R + ROS 1 or $\mathrm{I} / \mathrm{R}+\mathrm{ROS} 3,1$ or $3 \mathrm{mg} / \mathrm{kg}$ i.v., $\mathrm{n}=6-11$ ) or ciglitazone (I/R + CIG 1 or I/R + CIG 3,1 or $3 \mathrm{mg} / \mathrm{kg}$ i.v., $\mathrm{n}=6-7$ ) prior to and during reperfusion. Figures shown are representative of at least 3 experiments performed on different experimental days. Data are expressed as mean \pm SEM of $n$ observations, ${ }^{*} \mathrm{p}<0.05$ vs. I/R $+\mathrm{VEH}$. 


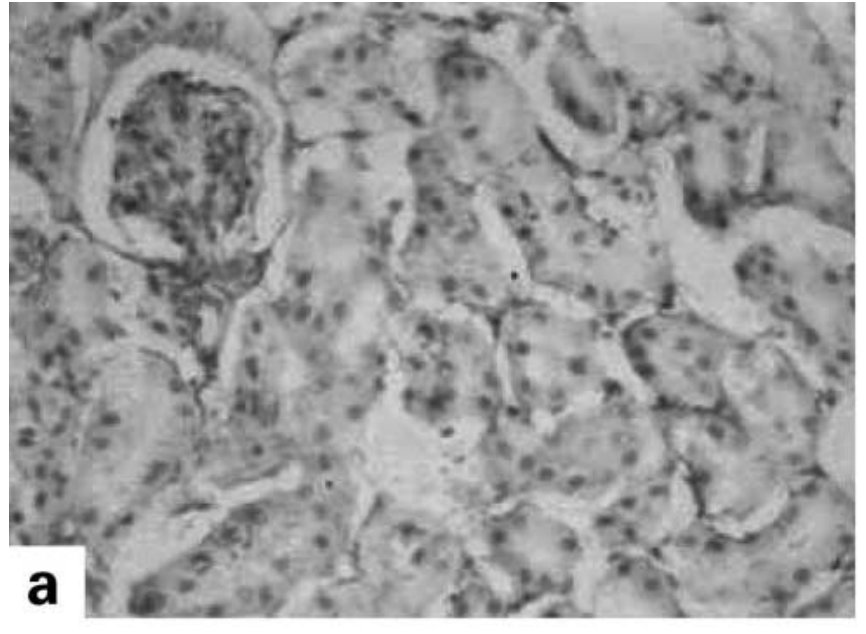

SHAM + VEH

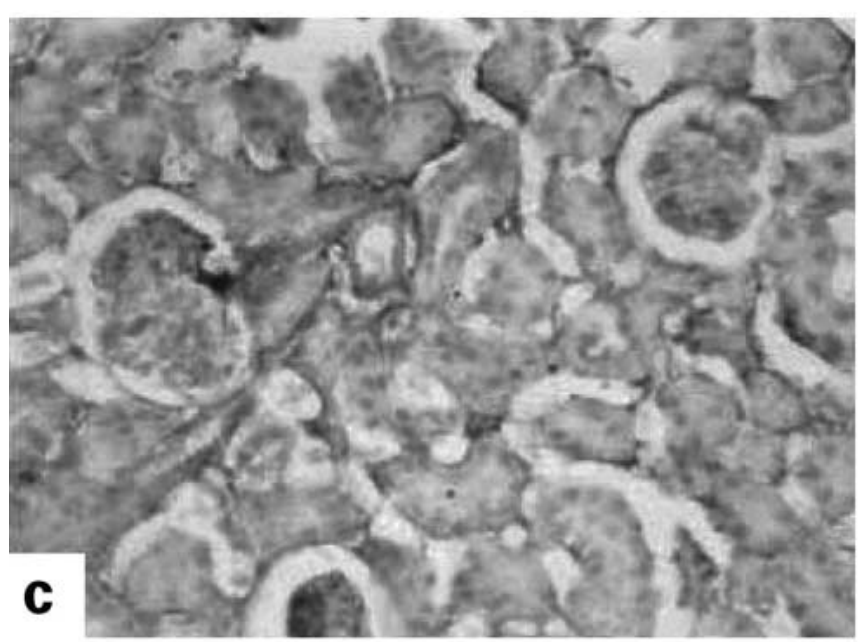

\section{I/R + ROS 3}

Fig. 5. Immunohistochemical localisation of PAR formation in sections of rat kidney. Rats were subjected to surgical procedure alone and administered 10\% (v/v) DMSO (Sham + VEH, 2 ml/kg i.v., $\mathrm{n}=$ 6), or in rats subjected to bilateral renal I/R (a), and treated with $10 \%$ (v/v) DMSO (I/R + VEH, $2 \mathrm{ml} / \mathrm{kg}$ i.v., $\mathrm{n}=7$ ) (b), rosiglitazone (I/R +

Effect of Rosiglitazone and Ciglitazone on ICAM

Expression and PMN Infiltration into Kidneys of Rats

Subjected to Renal I/R

When compared to sham-operated rats, I/R caused a significant increase in the expression of ICAM-1 (fig. 4a, b). Administration of rosiglitazone or ciglitazone (3 mg/ $\mathrm{kg})$ significantly reduced the expression of ICAM-1 caused by I/R (fig. 4a, b).

PPAR- $\gamma$ Agonists Reduce Renal

Ischemia/Reperfusion Injury

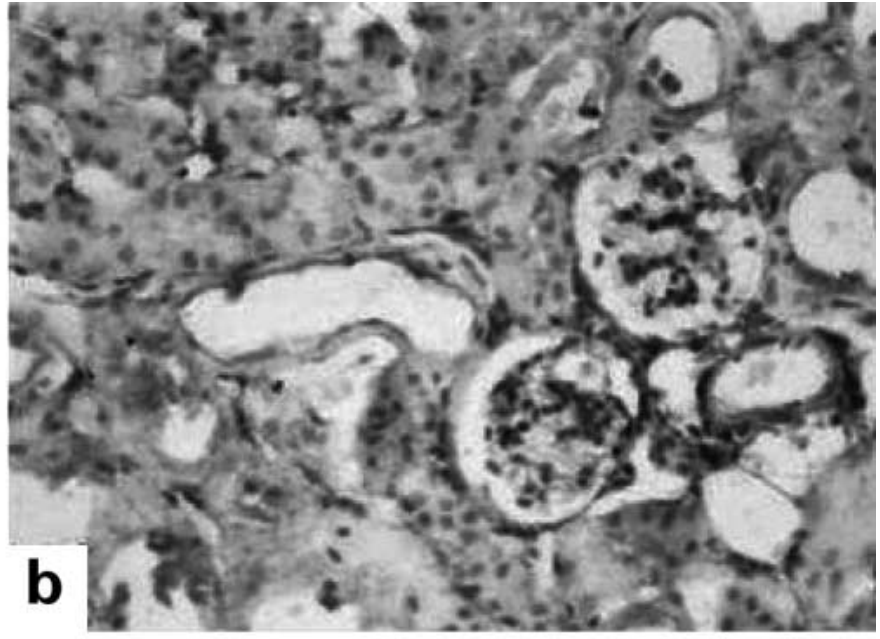

\section{I/R + VEH}

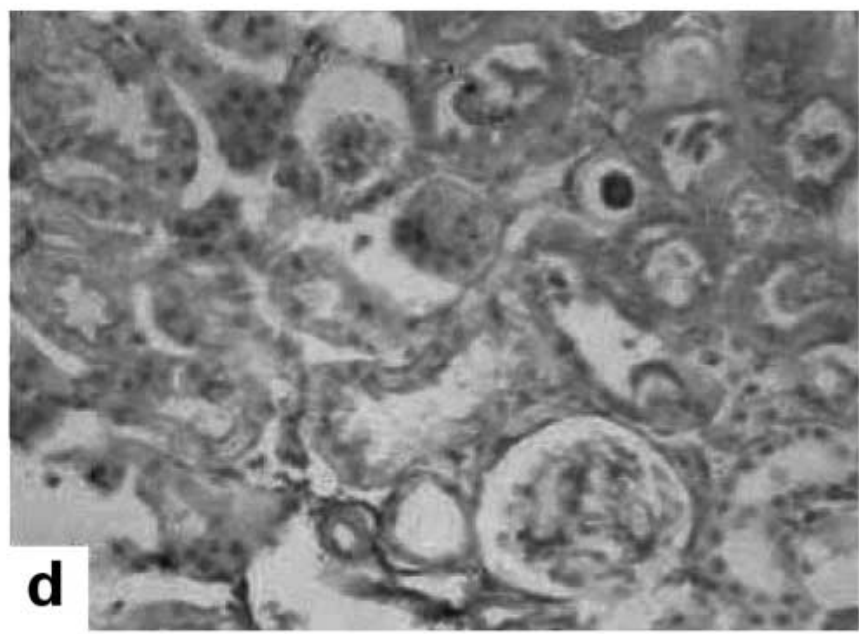

\section{I/R + CIG 3}

ROS $3,3 \mathrm{mg} / \mathrm{kg}$ i.v., $\mathrm{n}=7$ ) (c) or ciglitazone (I/R + CIG $3,3 \mathrm{mg} / \mathrm{kg}$ i.v., $\mathrm{n}=7)(\mathbf{d})$ prior to and during reperfusion. Figures shown are representative of at least 3 experiments performed on different experimental days. $\times 125$.

On comparison with sham-operated rats administered $10 \%(\mathrm{v} / \mathrm{v})$ DMSO only, rats subjected to renal I/R exhibited a substantial increase in kidney MPO activity (fig. 4c), suggesting increased PMN infiltration into reperfused renal tissues. However, administration of rosiglitazone or ciglitazone ( 1 and $3 \mathrm{mg} / \mathrm{kg}$ ) produced a significant and dose-dependent reduction of MPO activity in comparison with that obtained from kidneys obtained from rats subjected to I/R only (fig. 4c).

Am J Nephrol 2003;23:267-276 
Immunohistochemical Localisation of PAR Formation

Immunohistochemical analysis of renal sections obtained from rats subjected to renal $\mathrm{I} / \mathrm{R}$ injury revealed positive staining for PAR (fig. 5b), indicating PARP activation subsequent to DNA damage caused by oxidative stress. In kidneys obtained from rats administered rosiglitazone or ciglitazone $(3 \mathrm{mg} / \mathrm{kg}$ ) prior to and during reperfusion, markedly reduced staining for PAR was observed (fig. $5 \mathrm{c}, \mathrm{d}$ ), suggesting a reduction in the activation of PARP (and therefore a reduction in oxidative stress) after $6 \mathrm{~h}$ reperfusion. No evidence of staining for PAR was observed in kidney tissues obtained from sham-operated rats administered 10\% (v/v) DMSO only (fig. 5a).

\section{Discussion}

We show here that bilateral renal artery occlusion (for $45 \mathrm{~min}$ ) and reperfusion (for $6 \mathrm{~h}$ ) in anesthetized rat results in a significant increase in serum levels of urea and creatinine, indicating glomerular dysfunction which was reflected by a significant fall in creatinine clearance (and thus, glomerular filtration rate). Renal I/R also caused a marked increase in fractional excretion of $\mathrm{Na}^{+}$indicating marked tubular dysfunction of the PT. Tubular injury was confirmed by increased urinary excretion of NAG and moreover, characteristic histological signs of marked tubular injury were observed in kidneys subsequent to renal $\mathrm{I} / \mathrm{R}$. This is in keeping with the observation that the $\mathrm{S}_{3}$ segment of the proximal tubule (PT) is particularly susceptible to renal I/R injury [26]. All these data, together with an increased expression of the adhesion molecule ICAM-1, increased renal MPO activity (indicative of PMN infiltration into reperfused renal tissue) and increased PAR formation (suggesting increased PARP activation secondary to DNA damage caused by oxidative stress), confirm a well-recognised pattern of renal dysfunction and injury associated with I/R of the kidney [5$8,27]$ and are in agreement with the notion that renal $\mathrm{I} / \mathrm{R}$ causes both glomerular and tubular dysfunction [28].

The main findings of the current study can be summarised as follows: (i) the expression of PPAR- $\alpha$, PPAR- $\beta$ and PPAR- $\gamma 1$ can be documented in the kidney of the rat; (ii) bilateral I/R attenuates the expression of PPAR- $\alpha$, but does not affect the expression of any of the other isoforms of PPAR; (iii) the anti-diabetic TZDs rosiglitazone and ciglitazone (PPAR- $\gamma$ agonists) reduce the development of glomerular and tubular dysfunction caused by renal I/R, and (iv) rosiglitazone and ciglitazone also reduce the tubular injury and the histological evidence of renal inju- ry. All of these findings support the view that rosiglitazone and ciglitazone attenuate the degree of renal dysfunction and injury caused by $\mathrm{I} / \mathrm{R}$ of the kidney of the rat. The effects of rosiglitazone and ciglitazone on glomerular dysfunction were rather modest (yet significant). However, it should be noted that these agents had a greater effect on tubular dysfunction and injury and that the PT is at most risk of injury caused by renal I/R or oxidative stress [2628]. It should also be noted here that although rosiglitazone and ciglitazone produced significant reductions in tubular dysfunction and injury, there was still evidence of renal injury, highlighting the fact that the mechanisms involved in the development of ischemic ARF are multifactorial, e.g. I/R also leads to detrimental increases in intracellular $\mathrm{Ca}^{2+}$ concentrations and calpain/caspase activation $[5-8,27]$. Furthermore, each measurement of renal function has inherent difficulties (e.g. a one point in time serum creatinine is not a particularly reliable indicator, especially when changes are rather modest) and therefore we have used many different indicators of renal function and injury involving a range of serum, urinary and histological analysis.

Rosiglitazone produced a dose-dependent reduction of glomerular and tubular dysfunction and tubular injury. However, although $1 \mathrm{mg} / \mathrm{kg}$ ciglitazone significantly improved the renal dysfunction and injury associated with renal I/R, a higher dose $(3 \mathrm{mg} / \mathrm{kg})$ was less effective. A similar profile was observed when the beneficial effects of ciglitazone against myocardial I/R injury were explored [17] and may reflect a degree of toxicity associated with high doses of this compound or non-specific effects. Overall, both rosiglitazone and ciglitazone produced a similar level of reno-protection against renal dysfunction and injury caused by I/R which reflected their known potency as PPAR- $\gamma$ agonists in vitro [11].

Once the beneficial aspects of rosiglitazone and ciglitazone administration against the renal dysfunction and injury caused by $\mathrm{I} / \mathrm{R}$ of the kidney were established, we investigated the mechanism by which these TZDs/ PPAR- $\gamma$ agonists protect the kidney against I/R. Administration of rosiglitazone or ciglitazone did not modulate the expression of PPAR- $\beta$ or PPAR- $\gamma 1$, nor did it affect the down-regulation of the PPAR- $\alpha$ caused by I/R. Synthetic TZDs including rosiglitazone and ciglitazone were the first class of compounds to be identified as PPAR- $\gamma$ ligands and rosiglitazone is the most potent and selective PPAR- $\gamma$ agonist $[9,10]$. We and others have recently reported that rosiglitazone and ciglitazone can reduce the tissue injury caused by I/R of the heart [16-20]. Although the mechanisms involved in the cardioprotective effects 
of these TZDs are not entirely clear, the protective effects obtained in this study after short-term exposure to the PPAR- $\gamma$ agonists suggest mechanisms mediated via direct action at the PPAR- $\gamma[16-18,20]$. PPAR- $\gamma$ is selectively expressed in medullary collecting ducts and pelvic urothelium while PPAR- $\alpha$ have been shown to be predominantly expressed in the PT and medullary thick ascending limbs of the kidney [29]. PPAR- $\gamma$ activity is also associated with the renal vasculature; specifically, there is evidence that endogenous PPAR- $\gamma$ activity is associated with renal glomeruli and medullary vasculature [30]. In this study, the down-regulation of PPAR- $\alpha$ observed subsequent to $\mathrm{I} / \mathrm{R}$ is likely to reflect the compromised integrity of PT cell structure caused by I/R.

The results presented in this study also demonstrate that administration of rosiglitazone and ciglitazone can modulate the expression of an adhesion molecule known to be induced during renal I/R. Both PPAR- $\gamma$ agonists markedly reduced the expression of ICAM-1, the expression of which, amongst other adhesion molecules (e.g. VCAM-1, P-selectin, E-selectin), have been associated with renal I/R-injury [31-33]. In addition, rosiglitazone has been shown to attenuate the expression of the chemokine MCP-1 as well as the accumulation of PMNs associated with regional myocardial I/R [17]. Adhesion molecule expression is a fundamental requirement for the recruitment of PMNs into renal tissues during renal reperfusion, leading to the release of mediators of renal injury including reactive oxygen species which together contribute to ischemic ARF $[32,34]$. Our data presented here demonstrate the ability of both rosiglitazone and ciglitazone to reduce renal MPO activity suggesting a significant reduction of PMN infiltration into renal tissues during reperfusion.

PMNs infiltrating into reperfused renal tissues are a major source of reactive oxygen species which contribute significantly to the development of renal I/R injury and associated ischemic ARF [35]. Reactive oxygen species also cause strand breaks in DNA, which trigger energyconsuming DNA repair mechanisms and activate the nuclear enzyme poly(ADP-ribose) polymerase (PARP). PARP activation results in the depletion of its substrate $\mathrm{NAD}^{+}$and also in a reduction in the rate of glycolysis [23]. As $\mathrm{NAD}^{+}$functions as a cofactor in glycolysis and the tricarboxylic acid cycle, $\mathrm{NAD}^{+}$depletion leads to a rapid fall in intracellular ATP rapidly followed by cellular dysfunction and death - the PARP Suicide Hypothesis. We have recently discovered that PARP activation plays an important role in both the renal dysfunction and injury caused by $\mathrm{I} / \mathrm{R}$ of the kidney in vivo [23] and in the cellular injury and death caused by oxidative stress in rat PT cell cultures in vitro [36]. Using immunohistochemistry, we demonstrate here that renal I/R leads to an increase in PARP activation secondary to oxidative stress and that this can be markedly reduced by the PPAR- $\alpha$ agonists rosiglitazone and ciglitazone.

Together, these findings support the hypothesis that the beneficial effects of TZDs in animal models of I/R of the kidney (and other organs) are predominantly due to a reduction in oxidative stress and anti-inflammatory actions of these PPAR- $\gamma$ agonists. These findings are similar to those of Schiffrin and colleagues who recently demonstrated that docosahexainoic acid (a PPAR- $\alpha$ agonist) decreased oxidative stress and inflammation (including reduction of ICAM-1 expression) in the vasculature of rats administered angiotensin II [37].

In conclusion, these results suggest that the PPAR- $\gamma$ agonists rosiglitazone and ciglitazone reduce the renal dysfunction and injury associated with I/R of the kidney. We propose that one mechanism underlying the protective effects involves inhibition of the expression of ICAM-1 during I/R, a reduction of PMN infiltration into renal tissues and subsequent reduction of oxidative stress.

\section{Acknowledgements}

The authors would like to thank Dr. Rui Pinto, Laboratory of Pharmacology, Faculty of Pharmacy, University of Lisbon, Portugal, for urinary N-acetyl- $\beta$ - $D$-glucosaminidase measurements and Dr. Tiziana Genovese and Dr. Rosanna Di Paola, Department of Clinical and Experimental Medicine and Pharmacology, University of Messina, Italy, for performing the ICAM-1 immunohistochemistry and measurements of MPO activity. PKC is funded by the National Kidney Research Fund (Project Grant R41/2/2000). This work was, in part, supported by the Clínica Médica é Diagnóstico Dr. Joaquim Chaves, Lisbon, Portugal. 


\section{References}

1 Evans RM: The steroid and thyroid hormone receptor superfamily. Science 1988;240:889895.

2 Desvergne B, Wahli W: Peroxisome proliferator-activated receptors: Nuclear control of metabolism. Endocr Rev 1999;20:649-688.

3 Lameire N, Vanholder R: Pathophysiologic features and prevention of human and experimental acute tubular necrosis. J Am Soc Nephrol 2001;12:S20-S32.

4 Star RA: Treatment of acute renal failure. Kidney Int 1998;54:1817-1831.

5 Lieberthal W, Levine JS: Mechanisms of apoptosis and its potential role in renal tubular epithelial cell injury. Am J Physiol 1996;271: F477-F488.

6 Weight SC, Bell PR, Nicholson ML: Renal ischemia-reperfusion injury. Br J Surg 1996;83: 162-170.

7 Paller MS: The cell biology of reperfusion injury in the kidney. J Invest Med 1994;42:632639

8 Sheridan AM, Bonventre JV: Pathophysiology of ischaemic acute renal failure. Contrib $\mathrm{Ne}-$ phrol 2001;132:7-21.

9 Murphy GJ, Holder JC: PPAR- $\gamma$ agonists: Therapeutic role in diabetes, inflammation and cancer. Trends Pharmacol Sci 2000;21:469474.

10 Young PW, Buckle DR, Cantello BC, Chapman H, Clapham JC, Coyle PJ, Haigh D, Hindley RM, Holder JC, Kallender H, Latter AJ, Lawrie KW, Mossakowska D, Murphy GJ, Roxbee Cox L, Smith SA: Identification of high-affinity binding sites for the insulin sensitizer rosiglitazone (BRL-49653) in rodent and human adipocytes using a radioiodinated ligand for peroxisomal proliferator-activated receptor $\gamma$. J Pharmacol Exp Ther 1998;284:751759.

11 Willson TM, Brown PJ, Sternbach DD, Henke BR: The PPARs: From orphan receptors to drug discovery. J Med Chem. 2000;43:527550

12 Nakajima A, Wada K, Miki H, Kubota N, Nakajima N, Terauchi Y, Ohnishi S, Saubermann LJ, Kadowaki T, Blumberg RS, Nagai R, Matsuhashi N: Endogenous PPAR $\gamma$ mediates anti-inflammatory activity in murine ischemiareperfusion injury. Gastroenterology 2001;120: 460-469.

13 Ichikawa H, Naito Y, Takagi T, Tomatsuri N Yoshida N, Yoshikawa T: A specific peroxisome proliferators-activated receptor-gamma (PPAR-gamma) ligand, pioglitazone, ameliorates gastric mucosal damage induced by ischemia and reperfusion in rats. Redox Rep 2002; 7:343-346.
14 Naito Y, Takagi T, Uchiyama K, Handa O, Tomatsuri N, Imamoto E, Kokura S, Ichikawa H, Yoshida N, Yoshikawa T: Suppression of intestinal ischemia-reperfusion injury by a specific peroxisome proliferator-activated receptor-gamma ligand, pioglitazone, in rats. Redox Rep 2002; 7:294-299.

15 Okada M, Yan SF, Pinsky DJ: Peroxisome proliferators-activated receptor-gamma (PPAR-gamma) activation suppresses ischemic induction of Egr-1 and its inflammatory gene targets. FASEB J 2002;16:1861-1868.

16 Thiemermann C, Wayman NS: Menarini Academy Cardiovascular Research Awards in Basic Science 2001: Ligands of the orphan receptor peroxisome-proliferator activator-receptor $\gamma$ reduce myocardial infarct size. Med Sci Monit 2001;7:787-789.

17 Wayman NS, Hattori Y, McDonald MC, Mota-Filipe H, Cuzzocrea S, Pisano B, Chatterjee PK, Thiemermann C.: Ligands of the peroxisome proliferator-activated receptors (PPAR- $\gamma$ and PPAR- $\alpha$ ) reduce myocardial infarct size. FASEB J 2002; 16:1027-1040.

18 Khandoudi N, Delerive P, Berrebi-Bertrand I, Buckingham RE, Staels B, Bril A: Rosiglitazone, a peroxisome proliferator-activated receptor- $\gamma$ (agonist), inhibits the Jun NH(2)-terminal kinase/activating protein 1 pathway and protects the heart from ischemia/reperfusion injury. Diabetes 2002;51:1507-1514.

19 Sidell RJ, Cole MA, Draper NJ, Desrois M, Buckingham RE, Clarke K: Thiazolidinedione treatment normalizes insulin resistance and ischaemic injury in Zucker Fatty rat heart. Diabetes 2002;51:1110-1117.

20 Yue TL, Chen J, Bao W, Narayanan PK, Bril A, Jiang W, Lysko PG, Gu JL, Boyce R, Zimmerman DM, Hart TK, Buckingham RE, Ohlstein $\mathrm{EH}$ : In vivo myocardial protection from ischemia/reperfusion injury by the peroxisome proliferator-activated receptor- $\gamma$ agonist rosiglitazone. Circulation 2001;104:2588-2594.

21 Buckingham RE, Al-Barazanji KA, Toseland N, Slaughter M, Connor SC, West A, Bond B, Turner NC, Clapham JC: Peroxisome proliferators-activator receptor- $\gamma$ agonist, rosiglitazone, protects against nephropathy and pancreatic islet abnormalities in Zucker fatty rats. Diabetes 1998;47:1326-1334.

22 Ma LJ, Marcantoni C, Linton MF, Fazio S, Fogo AB: Peroxisome proliferator-activated receptor-gamma agonist troglitazone protects against nondiabetic glomerulosclerosis in rats. Kidney Int 2001;59:1899-1910.

23 Chatterjee PK, Zacharowski K, Cuzzocrea S, Otto M, Thiemermann C.: Inhibitors of poly (ADP-ribose) synthetase reduce ischemia-reperfusion injury in the anesthetised rat in vivo. FASEB J 2000;14:641-651.
24 Chatterjee PK, Patel NSA, Sivarajah A, Kvale EO, Dugo L, Cuzzocrea S, Brown PAJ, Stewart KN, Mota-Filipe H, Britti D, Yaqoob MM Thiemermann C: GW274150, a potent and highly selective inhibitor of iNOS, reduces experimental renal ischemia/reperfusion injury. Kidney Int 2003;63:853-865.

25 Chomczynski P, Sacchi N: Single-step method of RNA isolation by acid guanidinium thiocyanate-phenol-chloroform extraction. Anal Biochem 1987;162:156-159.

26 Venkatachalam MA, Bernard DB, Donohue JF, Levinsky NG: Ischemic damage and repair in the rat proximal tubule: Differences along the $S_{1}, S_{2}$ and $S_{3}$ segments. Kidney Int 1978; 14 : 31-49.

27 Kribben A, Edelstein CL, Schrier RW: Pathophysiology of acute renal failure. J Nephrol 1999;12:S142-S151.

28 Paller MS: Pathophysiologic mechanisms of acute renal failure; in Goldstein RS (ed): Mechanisms of Injury in Renal Disease and Toxicity. Ann Arbor, CRC Press, 1994, pp 3-13.

29 Guan YF, Breyer MD: Peroxisome proliferators-activated receptors (PPARs): Novel therapeutic targets in renal disease. Kidney Int 2001; 60:14-30.

30 Guan YF, Zhang Y, Schneider A, Davis L, Breyer RM, Breyer MD: Peroxisome proliferator-activated receptor- $\gamma$ activity is associated with renal microvasculature. Am J Physiol Renal Physiol 2001;281:F1036-F1046.

31 Molitoris BA, Marrs J: The role of cell adhesion molecules in ischemic acute renal failure. Am J Med 1999;106:583-592.

32 Rabb H, O'Meara YM, Maderna P, Coleman P, Brady HR: Leukocytes, cell adhesion molecules and ischemic acute renal failure. Kidney Int 1997;51:1463-1468.

33 Chamoun F, Burne M, O’Donnell M, Rabb H: Pathophysiologic role of selectins and their ligands in ischemia reperfusion injury. Front Biosci 2000;5:e103-e109.

34 Lauriat S, Linas SL: The role of neutrophils in acute renal failure. Semin Nephrol 1998;18: 498-504.

35 Nath KA, Norby SM: Reactive oxygen species and acute renal failure. Am J Med 2000;109: 665-678.

36 Chatterjee PK, Cuzzocrea S, Thiemermann C: Inhibitors of poly (ADP-ribose) synthetase protect rat proximal tubular cells against oxidant stress. Kidney Int 1999;56:973-984.

37 Diep QN, Amiri F, Touyz RM, Cohn JS, Endemann D, Neves MF, Schiffrin EL: PPAR $\alpha$ activator effects on Ang II-induced vascular oxidative stress and inflammation. Hypertension 2002;40:866-871. 